\title{
António Lobo Antunes e o Nouveau Roman: \\ a personagem do romance
}

\author{
Alexandre Claudius Fernandes ${ }^{1}$
}

RESUMO: Este artigo pretende analisar de que forma a estruturação de personagens nas narrativas de António Lobo Antunes dialoga com a estética do nouveau roman francês, revelando a multifacetada criação diegética do autor português.

ABSTRACT. This paper aims to analyze the extent to which the construction of characters in António Lobo Antunes' narratives is in dialogue with the aesthetics of the French nouveau roman, by revealing the multifaceted diegetical creation by the Portuguese author.

PALAVRAS-CHAVE: Personagem; Narrativa; Nouveau roman; Lobo Antunes KEYWORDS: Character; Narrative; Nouveau roman; Lobo Antunes

"L'oeuvre doit être considérée seulement comme um amour malheureux que em présage fatalement d'autres."

A.Proust

“Le Nouveau Roman n'a fait que jouer avec les rapports quantitatifs d'expressivité du personnage en le réduisant, le plus souvent, à sés seules capacités perceptives et émotives et en le situant dans un espace plus ou moins intemporel afin de se démarquer d'une conception psychologisante, réaliste et humaniste de la personne(...)

La production romanesque contemporaine cultive cette tradition $d u$ personnage divisé et, dans la société actuelle, celui-ci se trouve souvent coupé de tout lien social car il y a incompatibilité entre lui e la communauté qui l'entoure." Michel Erman

A caracterização e as aproximações dos atributos da personagem do romance, em especial do romance moderno e contemporâneo, pela complexidade com que se estabelecem e são criados, acabam gerando, entre a crítica e os pesquisadores, divergências e aproximações inusitadas. As influências e confluências entre escritores desde a

\footnotetext{
${ }^{1}$ Doutorando USP. Contato: a.claudius@yahoo.com.br
} 
segunda metade do século $\mathrm{XX}$ até os dias atuais, demonstram o intercâmbio de relações e diálogos entre as literaturas. Aqui estabeleceremos a proposta de diálogo entre o Nouveau Roman francês e o escritor português Antônio Lobo Antunes, na obra Ontem não te vi em Babilónia.

A complexidade no abordar o tema da personagem poderá ser percebida se seguirmos desde o início a trilha, já percorrida, por teóricos e especialistas. Aristóteles, o patriarca das questões críticoliterárias $^{2}$, direcionava seu olhar para a ação em que as personagens estavam envolvidas. Era uma abordagem sobre a ação (práxis) destes seres fictícios, tendo como referencial o mundo empírico, isto é, um gesto efabulativo-mimético. Somente com o russo Vladimir Propp é que o enfoque, ainda sobre a ação, toma uma nova dimensão, pois a imitação a partir do mundo concreto e empírico torna-se irrelevante, por conta da busca da literariedade. Para Propp, em Morfologia do conto, há sete $^{3}$ esferas de ações (agressor; doador; auxiliar; mandante; pai; herói; e anti-herói) que delimitariam as personagens, suas funções e essas "esferas de ações" estavam ainda atreladas intimamente à intriga e ao caráter das personagens, isto é, a classificação instituída submetia-se à trama (enunciado) e ao comportamento das personagens. Edwin Muir corroborando tais aspectos, de que as personagens são determinadas pelo enredo, ao estudar o que chamava de romance dramático, reconhece também que as qualidades das personagens determinam a ação e a ação modifica e modaliza as personagens (MUIR, p. 22, 1971). E ainda, Phillipe Hamon, no ensaio Por um estatuto semiológico da personagem ${ }^{4}$, qualifica as nomeações de herói e falso-herói como uma questão de ênfase, focalização e modalização do enunciado. Hamon, entretanto, estabelece uma classificação ${ }^{5}$, que será cara ao nosso olhar

\footnotetext{
${ }^{2}$ Obviamente já é existente em Platão (A República) tal perspectiva, entretanto, é Aristóteles quem permite re-estruturar a posição do poeta e sua criação mimética.

${ }^{3}$ Greimas reduz a seis actantes: remetente; objeto; auxiliar; destinatário; sujeito; e oponente.

4 HAMON, Philippe. Por um estatuto semiológico da personagem. In: BARTHES, Roland et alii. Masculino, feminino, neutro: ensaios de semiótica narrativa. Porto Alegre: Globo, 1976.

${ }^{5}$ Das qualificações atribuídas às personagens do romance deve-se, ao falar de teóricos do século XX, salientar a de Forster, que estabelece dois tipos: personagem plana (flat characters) e a personagem
} 
mais adiante, sobre as personagens anáforas, estas que tecem no enunciado uma rede de apelos e lembranças, contudo para eles esses elementos tinham o encargo de organização e coesão do enunciado. A proposição última de Hamon será controversa quando aplicada a romancistas como Robert Pinget, Nathalie Sarraute e o português António Lobo Antunes.

\section{Dois panoramas: Nouveau Roman e Lobo Antunes}

Como primeira definição do que foi o Nouveau Roman francês deve-se deixar claro que não foi uma "escola literária", mas uma tendência de determinados romancistas com mais particularidades do que semelhanças. Este fluxo inicia com a obra de Nathalie Sarraute, em 1938, Tropisme. O Nouveau Roman é também considerado como "romance do romance", a concretização técnica do récit speculaire. A multiplicação de papéis, o pluri-perspectivismo e a presença de "sabotagens temporais" são rótulos estereotipados por Nathalie Sarraute6. A principal característica era a negação das técnicas tradicionais (PERRONE-MOISÉS, 1966, p. 16). Dos nomes que se destacaram pode-se citar: Allain Robbe Grillet, Michel Butor, Robert Pinget, Claude Simon e, até mesmo, Maurice Blanchot é considerado um "adepto". As personagens destes romancistas eram muito performáticas, tal qual o texto, uma forte tendência psicológica tomava conta e a indistinção entre estimulos corporais e reações psíquicas. A solidão será o principal drama, atingindo, por vezes, o estado de despersonalização, e o ambiente deserto e desolado cercará continuamente as personagens do Nouveau Roman. O novo-romancista tenta trazer aos seus romances a banalidade do dia-dia, a ausência de "espectacularidade"; a personagem, inquieta e perturbada, presa de numerosas inquietações, configura-se neste panorama, de intriga

esférica (round characters). A primeira marcada pela linearidade do ser e fazer; e a segunda por sua densidade psicológica e complexidade.

6 SARRAUTE, Nathalie. "Ce que jê cherche à faire" in Nouveau Roman: Hier Aujourd'hui 2.Pratiques. Col. 10X18, Ed. Cerisy La Salle, 1972, p.26. 
escassa e movimentação da escrita: façon dire (MONTEIRO, 1991, p. 249).

A prosa contemporânea portuguesa de António Lobo Antunes, desde seu primeiro romance, Memória de elefante (1979), revela atributos de uma escritura consciente e austera, tanto na tradição quanto nas inovações. Após dois anos como médico na guerra de Angola, Lobo Antunes, retorna a Portugal e segue a carreira psiquiátrica publicando artigos sobre Bocage, Antero de Quental e Lewis Carroll, expedições em busca de compreensão psicológica da sublimação artística. O romance $O$ manual dos inquisidores é o décimo primeiro do escritor português, publicado em 1996, foi traduzido para diversos idiomas e tem alcançado grande sucesso. Recebeu por este livro o prêmio Melhor Livro Estrangeiro publicado na França, (1997) e o prêmio Tradução Portugal/Frankfurt (1997). A narrativa usa a trajetória decadente de um influente ministro e de sua familia durante a ditadura salazarista e dos que os cercam para problematizar as relações humanas. Os romances antunianos se voltam sempre para personagens de cariz psicológico que, de modo frio e sombrio, manifestam seus estados negativos, perdas e desolações por meio da agressividade metafórica.

A escrita de António Lobo Antunes é densa e labirintica, o insólito está sempre presente, tentando liberar o ser das coisas. Os romances mais recentes do autor, Eu hei-de amar uma pedra (2004) e Ontem não te vi em Babilônia (2006), em vez de discorrer sobre casos referenciais ou historicamente alegorizáveis, transfere estes aportes para o campo das relações humanas, quase sempre fracassadas. A pontuação existe de forma rarefeita, o que transforma a cadeia de significantes em espiral e deixa o leitor escolher o ponto de parada significativa. Quem lança as personagens ao passado é sempre o Outro, que surge na escrita antuniana como um narrador que não narra. Os paradoxos e as revelações no decorrer da obra causam explosões significantes que geram textos, primeiramente mentais e em seguida, pela memória, psicografias de fantasmas internos (das Umheimlich). 


\section{Personas, máscaras e personagens}

No romance Ontem não te vi em Babilónia, o princípio de mimetismo para estruturação da personagem ainda segue. Tomando por base a classificação do professor da Universidade Bourgogne (Dijon), Michel Erman7, a forma da apresentação das personagens, isto é, o mimetismo das personagens, pode-se classificá-las em: individu; personne; e moi. A personagem individu é delineada em função de sua superposição de momentos, por meio da intriga e de suas descrições; a personagem personne determina-se por seus sentimentos e a consciência de si mesma, isto é, uma distinção individual; e a personagem moi, próxima da sua relação eu - outro, em geral em primeira pessoa e um ser esquizóide (ERMAN, p.105-109, 2006). Tais identificadores permitem aproximar a escrita antuniana a dos novoromancistas franceses, contudo, permite uma visage mais ampla na construção efabulativa dos seres ficcionais do romancista português.

A configuração e a formatação das personagens, isto é, segundo tais termos, o demonstrar com figuras (configurar) e o estabelecer formato (formatar) na obra Ontem não te vi em Babilónia são feitas pelas próprias personagens, que muitas das vezes são desconhecidas e se desconhecem, não se compreendem enquanto seres existenciais ou como signos:

um nome que me intriga desde que me conheço, repito-o sem o entender, tento mudar-lhe a forma e resiste, compacto, duro (ONTB, p. 149)

- Ana Emília

(espero eu que a única pessoa com nome neste livro, a única autêntica)

(ONTB, p. 89)

(...) não o outro quarto que a alcofa transformava num lugar qualquer, no espelho uma criatura que se assemelhava a mim sem ser eu

- quem és tu

Ou seja a minha aliança e o meu cabelo, estas bochecha e estas pálpebras não, o meu marido para a do espelho

7 In: SBORNÍK PRACÍ FILOZOFICKÉ FAKULTY BRNENSKÉ UNIVERZITY STUDIA MINORA FACULTATIS PHILOSOPHICAE UNIVERSITATIS BRUNENSIS L 24, 2003 (http://www.phil.muni.cz/rom/erb/erman03.pdf). 
- Ana Emília (ONTB, p. 176)

A intercalação da personagem personne e moi, proposta por Erman, acomoda-se apropriadamente no projeto de Lobo Antunes. Tanto a apresentação das personagens é feita por elas mesmas, em primeira pessoa, quanto os valores patêmicos e passionais são revelados ou obscurecidos por seus monólogos e confissões. Estas personagens anáforas tecem no enunciado uma rede de apelos e lembranças aos segmentos de enunciados disjuntos, são como que signos mnemotécnicos (HAMON, 1976, p. 82). Tal hipertrofia do anafórico nem sempre assegura uma organicidade discursiva padrão, fazendo as obras, de António Lobo Antunes, serem consideradas herméticas.

A intriga, durante a noite que passam semi-acordados, letárgicos, dilui-se nas rememorações interpoladas. Desvanece o império da ação (práxis) da narrativa para se apresentar, ainda que em uma dramaticidade e teatralidade mental e textual, um fio cíclico e pendular de lembranças e imagens entrecortadas mentais:

e o meu pai a implorar com os olhos como se fosse morrer, não morreu nessa altura, morreu seis anos depois e sem fitas, parabéns, aguentou-se sozinho, pediu um papo-seco e ao regressar com o papo-seco já não estava, acho que não me quis a assistir, estavam feições mais inteligentes que as suas porque os defuntos uma majestade que até então ignorávamos, são eles e não são eles, é esquisito, se tivessem vivido assim tratávamos com consideração, não respondem, não se zangam, não dormem, pensam o tempo inteiro em assuntos dificeis, a gente

- O que é?

e eles sem passarem cartucho a reflectir, basta visitar o cemitério para se perceber que discorrem não de assuntos normais (ONTB, p.218)

(...) a minha mãe não é uma coisa que não presta, não carne poder, não bichos, acho que a minha irmã ou uma vizinha ou uma prima, não interess

- Não lhe rasgues a orelha com o brinco

Puseram-lhe um espelhinho diante da boca para verificar se respirava e no espelhinho

(disso recordo-me também, não vou esquecer, não esqueço!)

Não bem um hálito

(a lembrança de um hálito)

e um pingo rosado, ao retirarem o espelhinho eu a limpá-lo com os dedos e as unhas, mais unha que dedos 
- A minha mãe não é isto

até que no espelho nada, só eu ou não eu, a minha boca a aumentar ou seja não a minha boca, a indignação, a zanga e o milhares de dentes de ambas, os da indignação e os da zanga, o médico a franzir-se para mim

- Por que razão os obriga a vestirem-se de mulher? (ONTB, p.196)

Desta forma, outro aspecto relevante na apresentação das personagens, estas que se revelam como máscaras sociais (personne) e como seres para si e para o Outro (moi), é a questão da disposição tipográfica e a pontuação rarefeita em Lobo Antunes. Este efeito havia já sido explorado pelos novo-romancistas como técnica experimental: a omissão de pontos finais, o deslocamento das sentenças, a utilização de parênteses e itálicos. Blocos narrativos tornam-se potencializados em significação, as rememorações são dispostas e rearranjadas de tal forma que parágrafos deslocados são interligados por sua linha temática. Em Robert Pinget, afora as vírgulas esporádicas, não há pontuação. Deve-se levar em consideração aqui que a intriga e o caráter policial desta na escrita do autor francês ${ }^{8}$, difere de Lobo Antunes. Entretanto, tais narrativas são, de fato, falsas, pois não há crimes ou culpados e sim as ricas possibilidades do tema que parte de um acontecimento (PERRONE-MOISÉS, 1966, p.135). O acontecimento, em António Lobo Antunes, como desencadeador da narrativa, parece estar fora do foco de suas obras, especialmente as mais recentes: Meu nome é Legião (2007) e Arquipélago da insónia (2008).

A proposta não é classificar a escrita e escritura antuniana semelhante, ou até mesmo em um processo de emulação, ao dos novoromancistas franceses da metade do século XX. Porém, busca-se um introjetar-se de panoramas, estruturas e diálogos. O processo da narrativa e do gênero romanesco é evolutivo e agregador de tendências e experimentalismo deixados pelo tempo, marcas incorporadas que notamos pelo percurso, pelo rastro. As personagens, essas máscaras

\footnotetext{
${ }^{8}$ Não está se levando em consideração aqui a questão da memória e rememorações, da profundidade psicológica e pessimismo que aproximariam ambos os escritores em suas técnicas e narrativas.
} 
densas e periclitantes, são pegadas abissais e profundas neste processo. Sempre em busca, tanto dos autores franceses, como portugueses ou qualquer outro, de um novo romance.

\section{Referências bibliográficas}

ARISTÓTELES. Arte retórica e poética. Rio de Janeiro: Ediouro, 1989.

ANTUNES, António Lobo. Ontem não te vi em Babilónia. Lisboa: Dom Quixote, 2006.

ERMAN, Michel. Poétique du personnage de Roman. Paris, Ellipses, 2006.

HAMON, Phillipe. "Por um estatuto semiológico da personagem". In. BARTHES, R., et alii. Ensaios de semiótica narrativa. Porto Alegre: Editora Globo, 1976.

MONTEIRO, Ofélia Paiva. Literatura francesa moderna e contemporânea. Lisboa: Universidade Aberta, 1991.

MUIR, Edwin. A estrutura do romance. Porto Alegre: Editora Globo, 1971.

PERRONE-MOISÉS, Leyla. O novo romance francês. São Paulo: Buriti, 1966.

PROPP, V. Morfologia do conto. Lisboa: Vega, 1990.

ROSENFELD, Anatol et alii. A personagem de ficção. São Paulo: Perspectiva, 1976.

SEGOLIN, Fernando. Personagem e anti-personagem. São Paulo: Olho d`Água, 1978.

SÁBATO, Ernesto. O escritor e seus fantasmas. São Paulo: Companhia das Letras, 2003. 